\title{
Aşil tendinopatilerinde cerrahi seçenekler
}

\section{Surgical options in Achilles tendinopathies}

\author{
Tekin Kerem Ülkü, Barış Kocaoğlu
}

Acıbadem Üniversitesi Tıp Fakültesi Ortopedi ve Travmatoloji Anabilim Dalı, İstanbul

\begin{abstract}
Aşil tendonu, yüksek dayanıklılık ve esnekliğine rağmen, patellar tendon ile birlikte, aşırı kullanımdan en fazla etkilenen iki tendondan biridir. Tendinopatiler, spor aktivitelerine katılım gösteren hasta gruplarında görülebildiği gibi, sedanter bir hayat tarzı olan kişilerde de görülebilir. Aşil tendinopatileri terminolojisinde, tendonun kalkaneal insersiyosuna 2-7 $\mathrm{cm}$ mesafede nodüler şişlik, ağrı ve tendon performansında bozulmaya neden olan duruma gövde tendiniti, şişlik ısı artışı ve hiperemi ile tendon üzerinde görülen patolojiye Aşil paratendinopatisi, tendonun kalkaneal insersiyosunda olan ağrılı klinik duruma da insersiyonel Aşil tendinopatisi adı verilir. Aşil tendinopatilerinde öncelikli tedavi yaklaşımı konservatiftir. Eksentrik germe egzersizleri ve ESWT (Ekstrakorporeal Şok Dalga Tedavisi)'nin etkinliğini gösteren yayınlar mevcuttur. Ancak, konservatif tedavi ile \%24 ile \%45 arasında başarısız sonuçlar bildirilmiştir. Uzun süreli Aşil tendinopatileri, kötü cerrahi sonuçlarla ilişkilendirilmektedir. Altı aydan uzun süren konservatif tedaviye yanıtsız olgularda cerrahi tedavi düşünülmelidir. Aşil gövde tendinopatilerinde cerrahi tedavi seçeneklerinde açık yöntemler perkütan yöntemler ve endoskopik yöntemler kullanılabilir. Son dönemde plantaris gevşetilmesini de içeren endoskopik yöntemler ön plana çıkmaktadır. İnsersiyonel Aşil tendinopatisinin tedavisinde de farklı cerrahi yöntemler tanımlanmıştır. Etkin debridman, semptomların gerilemesinde oldukça önemli olup, neredeyse tendonun tamamının kaldırılmasını gerektirmektedir. En az iki ankor kullanılarak yapılan tamirin optimal sonuçları sağladığı gösterilmekle birlikte, artan yaygınlıkta kullanımı çift sıra tamirin başarısını göstermektedir.
\end{abstract}

Anahtar sözcükler: Aşil; tendinopati; Haglund; cerrahi
Despite its high endurance and elasticity Achilles tendon together with patellar tendon are the two tendons mostly affected from overuse. Tendinopathies can be seen both in sports participating population and in sedentary population. Achilles body tendinitis is defined as nodular swelling, pain and impairment in tendon function in $2-7 \mathrm{~cm}$ proximal from tendon insertion. Achilles paratendinopathy is generally seen together with hyperemia and increased heat over the tendon. Also pain over the calcaneal insertion of the Achilles tendon is referred as insertional Achilles tendinopathy. Primary treatment modality in Achilles tendinopathies is conservative. There are studies showing the success of eccentric stretching exercises and ESWT (Extracorporeal Shock Wave Therapy). However, some studies showed 24-45\% failure in conservative treatment. Long lasting Achilles tendinopathies are associated with inferior clinical outcomes. Surgical treatment should be considered in tendinopathies lasting more than 6 months. Surgical treatment of Achilles body tendinopathies consists of open, percutaneous, and endoscopic techniques. Endoscopic techniques involving debridement and plantaris release are gaining popularity. For insertional tendinopathies efficient debridement is very important for successful outcomes, however it needs near complete detachment of tendon from calcaneus. Reattachment using at least two anchors is shown to be effective, however double row repair is gaining popularity.

Key words: Achilles; tendinopathy; Haglund; surgery

Tüm Aşil tendon problemlerinde kronik enflamasyon bulgusu olmadığı için, bu süreç "tendinit" yerine "tendinosis" ya da "tendinopati" olarak tanımlanmıştır. ${ }^{[3]}$ Ancak, terminolojide ve sınıflandırmada zaman zaman karışıklıklar yaşanmaktadır. Genel olarak kabul gören yaklaşım, tendon üzerindeki anatomik lokasyona ve patolojiye göre sınıflandırılmasıdır. ${ }^{[4]}$ Buna göre; Aşil

- Illetişim adresi: Yrd. Doç. Dr. Tekin Kerem Ülkü, Tophanelioğlu cad. Okul sok. No:1 Üsküdar, İstanbul Tel: 0505 - 3184091 e-posta: keremulku@gmail.com

- Geliș tarihi: 1 Ocak $2018 \quad$ Kabul tarihi: 1 Ocak 2018 
tendonu kalkaneal insersiyosuna 2-7 cm mesafede nodüler şişlik, ağrı ve tendon performansında bozulmaya neden olan duruma Aşil gövde tendiniti, şişlik ısı artışı ve hiperemi ile tendon üzerinde görülen patolojiye Aşil paratendinopatisi, Aşil tendonunun kalkaneal insersiyosunda olan ağrılı klinik duruma da insersiyonel Aşil tendinopatisi adı verilir.

İnsersiyonel bölgede, Aşil tendinopatisinden başka Aşil tendonu dışındaki dokulardan kaynaklanan ancak tendon çevresinde ağriya neden olan, retrokalkaneal bursit ve superfisiyel kalkaneal bursit de zaman zaman tendinopatilere eşlik eden klinik durumlar olarak tanımlanmıştır.

Yukarıda tanımlanan tendinopati gruplarının her birinde, patolojik süreçler de birbirlerinden farklı olarak gelişir. Aşil gövde tendinopatisinde tendonun kendisinde inflamasyon olmadan tendinozis süreci ön planda iken, paratendinopatide paratenonda inflamatuvar oluşum gözlenir. İnsersiyonel tendinopatide ise temel patoloji, entezial fibrokartilajda kalsifikasyon ve kemik tendon bileşkesindeki küçük yırtıklardır.

Tüm bu klinik ve histopatolojik farklılıklardan dolayı da, Aşil tendinopatilerinin tedavisi anatomik lokasyon ve dokudaki histopatolojik değişikliklere göre özelleştirilmelidir.

Aşil tendinopatilerinde öncelikli tedavi yaklaşımı konservatiftir. Eksentrik germe egzersizleri ve ESWT (Ekstrakorporeal Şok Dalga Tedavisi)'nin etkinliğini gösteren yayınlar mevcuttur. ${ }^{[5]}$ Ancak, konservatif tedavi ile \%24 ile \%45 arasında başarısız sonuçlar bildirilmiştir. ${ }^{[6]}$ Uzun süreli Aşil tendinopatileri, kötü cerrahi sonuçlarla ilişkilendirilmektedir. ${ }^{[7]}$ Altı aydan uzun süren konservatif tedaviye yanıtsız olgularda cerrahi tedavi düşünülmelidir.

\section{AŞiL GÖVDE TENDINOPATILERININ CERRAHI TEDAVisi}

Aşil gövde tendinopatilerinde tedavi, konservatif ve cerrahi seçenekleri içerir. Başlangıçta cerrahi dışı yöntemler tercih edilmekle birlikte hastaların yaklaşık $\% 25$ 'inde cerrahi tedaviye ihtiyaç duyulur. ${ }^{[8-10]}$ Cerrahi tedavi endikasyonu hastanın en az 6 aylık konservatif tedaviye yanıt vermemesidir.[11] Cerrahi gerekliliğini arttıran kötü prognostik faktörler, ileri yaş, aşil tendonunda dejeneratif değişiklikler ve uzun süren semptomları olan hastalardır.

Tedavide farklı cerrahi yöntemler tanımlanmıştır. Açık cerrahi yöntemler dejeneratif nodül ve fibrotik yapışıklıkların debridmanı ile birlikte tenotomilerin yapılması ve iyileşme yanıtının uyarılması temeline dayanır. Teorik olarak ağrının nedeninin tendonun anteriorunda oluşan yeni nörovasküler oluşumların olacağı düşünülmektedir.

\section{Açık Debridman}

Açık debridman ve tenotomi tekniği; nodül, fibrotik dokular ile anormal olarak değerlendirilen tüm dokuların, paratenon eksize edilerek ${ }^{[12]}$ veya eksize edilmeden ${ }^{[13]}$ yapılan debridmanıdır.

Hasta prone pozisyonda yatarken posteromediyal veya posterior orta hat üzerinden tendondaki şişliğin proksimal ve distaline uzayacak şekilde insizyon yapılır. Cilt altı dokularda flep oluşturmadan keskin disseksiyonla paratenon geçilir ve tendondaki şişkin ve hafif renk değişikliği olan patolojik bölge tespit edilir. Birbiri ile kesişen yarı eliptik kesilerle, tendondaki patolojik alan eksize edilir. Geri kalan sağlıklı tendonun anterior ve posterioru ayrı olacak şekilde tübülerize edilerek tamir edilir.

Genellikle, geniş debridman yapıldığında dahi tendonun gücü yeterlidir. Tendonun \%50'den fazla kısmının debride edildiği durumlarda, fleksör hallusis longus (FHL) kullanılarak tendon augmentasyonu yapılmalıdır. ${ }^{[14]}$ Tallon ve ark. tarafından yapılmış çalışmada, açık debridman sonrası başarı oranları \%77 olarak $^{[15]}$, Maffuli ve ark.'nın serisinde ise başarı oranları \%36 olarak bildirilmiştir. ${ }^{[16]}$

\section{Perkütan Tenotomiler}

Testa ve ark., ultrasonografi eşliğinde tendonun patolojik kısımlarının tespit edilmesi ardından yapılan çoklu perkütan tenotomilerle, kısa ve uzun dönemlerde \%75'e varan iyi ve mükemmel sonuçlar bildirmişler$\operatorname{dir}$ (Şekil 1). ${ }^{[17,18]}$

\section{Minimal İnvaziv Yöntemler}

Longo ve ark., geniş çaplı sütürlerin cilt altı dokulardan geçirilmesi ile tendon anterioru ile yağ dokusu arasında oluştuğu düşünülen neovaskülarizasyonun ve yapışıkııların minimal invaziv olarak açılmasını tarif etmişlerdir. ${ }^{[19]}$ Ancak, bu yöntemin sonuçları ile ilgili bugüne kadar yayımlanmış bir çalışma yoktur.

\section{Endoskopik Debridman}

Açık cerrahi tekniklerin kullanılması ile iyi sonuçlar bildirilmekle birlikte, cerrahi komplikasyonlar, ameliyat sonrası iyileşme süresinin, özellikle spora dönüşün ortalama olarak 5-6 ay civarında olması nedeni ile, son dönemde endoskopik teknikler popüler olmuştur.

Van Skatenburg, Van Dijk ve ark., Aşil gövde tendinopatilerinin patogenezinde plantaris tendonunun rolü ile ilgili düşüncelerini, küçük olgu serilerinde yaptıkları endoskopik plantaris gevşetme ile olumlu sonuçlar alarak desteklemişlerdir. ${ }^{[20]}$ 


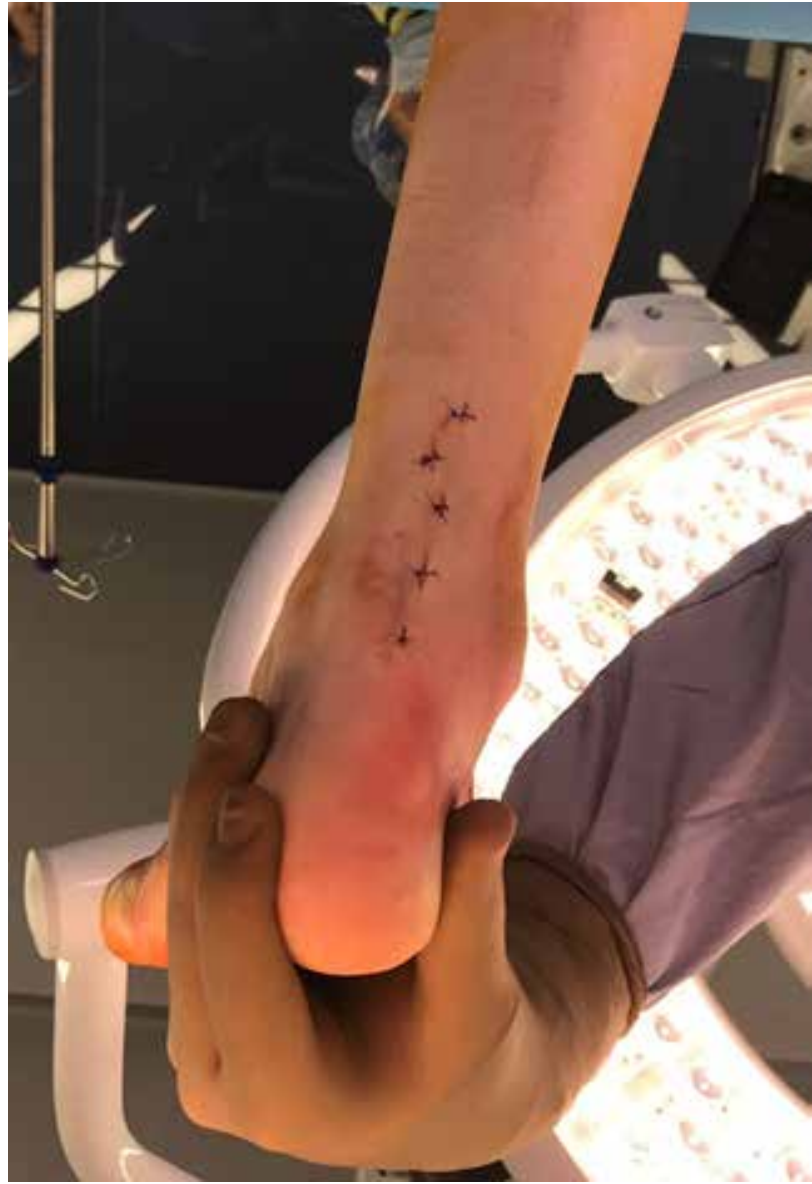

Şekil 1. Perkütan multipl insizyonlardan yapılan longitudinal tenotomi.

Hasta prone pozisyonda yatırılarak, distal lateral portal için 11 numara bistüri ile cilt insizyonu yapılır. Moskito klempi ile künt disseksiyon yapılarak, tendon üzerine ulaşılır ve skop portalden proksimale doğru ilerletilir (Şekil 2). Bu aşamada ideal pozisyon, işlemin yapılacağı tendonun yüzeyi ve paratenon arasındaki alanda kalmaktır. Proksimal portali, iyatrojenik sural sinir lezyonuna neden olmamak için tendon üzerinden mediyalden hazırlamak ve ardından spinal iğne, moskito klemp ile künt disseksiyon yapmak doğru olacaktır. Her iki portal de hazırlandığında, proksimal portalden shaver ile tendon ve paratenon arasındaki tüm yapışıklıklar temizlenerek tedaviye başlanır (Şekil 3 ve Şekil 4). Bu noktada, tendonun anteriorunda paratenon ile arasındaki neovaskülarizasyon alanının da temizlenmesi önerilir. Yapışıkıkların ortadan kaldırılması ardından, anteromediyalde plantaris tendonu bulunur. Plantaris, Aşil tendonundan ayırt edilerek gevşetilir.

Ameliyat sonrası alçı uygulaması ardından erken rehabilitasyon ile, erken sürede spora dönüş mümkün olur.

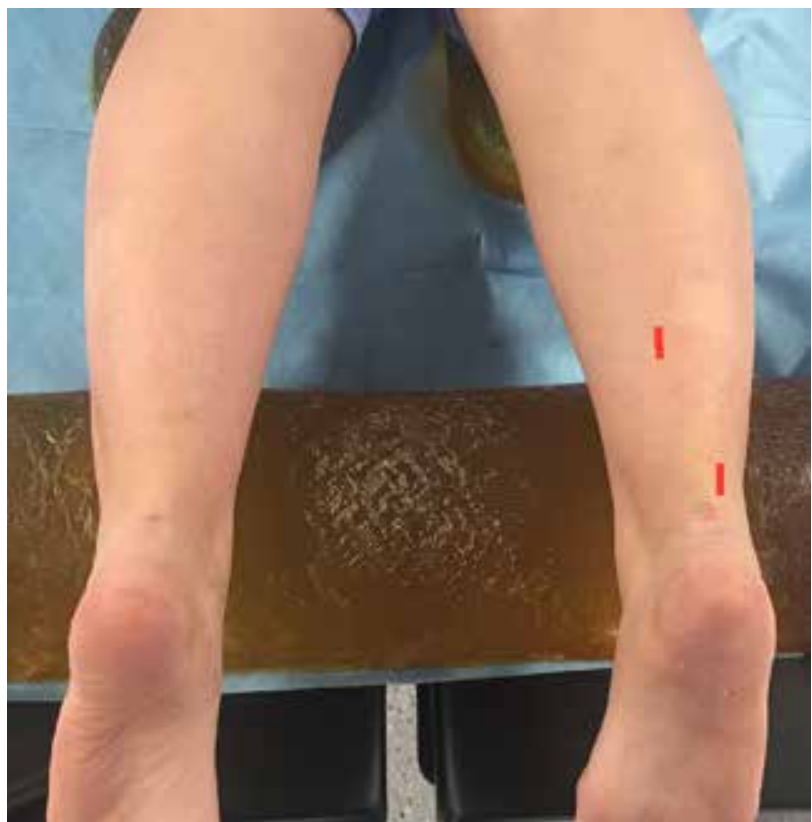

Şekil 2. Endoskopik Aşil tendon debridmanında kullanılan proksimal mediyal ve distal lateral insizyonun planlanması.

\section{INSERSIYONEL AȘIL TENDINOPATILERININ CERRAHI TEDAVISI}

İnsersiyonel tendinopatiler, Aşil tendonunun distalini ilgilendiren entesopatilerdir. Haglund sendromu ise kalkaneus posterior tuberkülündeki hipertrofiden dolayı inflame olan retrokalkaneal bursanın ve Aşil tendinopatisinin kombine olduğu durumu ifade eder. ${ }^{[21]}$ Tedavi, başlangıçta çoğu hastada konservatiftir; ancak, 3-6 ay boyunca konservatif tedaviye yanıt vermeyen semptomatik hastalarda cerrahi tedavi seçenekleri düşünülebilir. ${ }^{[22]}$

İnsersiyonel tendinopatilerin tedavisinde, başarılı sonuçlar bildirilen farklı cerrahi yöntemler mevcuttur. Geriye dönük olarak 35 hasta üzerinde yapılan bir çalışmada, lateral yaklaşım ile yapılan tendon debridmanı ile \%90 hastada iyi sonuç bildirilmiştir. ${ }^{[23]}$ Mediyal veya lateral yaklaşım ile gerçekleştirilen cerrahiler yara komplikasyonları ve ayakkabı kullanımı açısından avantajlı görünmekle birlikte, cerrahın tendonun tamamına hakim olmasını zorlaştırmaktadır. Her iki yaklaşımla da başarılı sonuçlar bildirilmekle birlikte, orta hat insizyonunu ve tendonu orta hattan ayırarak yapılan yaklaşımları savunan yazarlar da mevcuttur (Şekil 5). Tendonu orta hattan ayıran orta hat insizyonu ile yapılan 40 hastalık bir çalışmada, ameliyat sonrası 16 . ayda başarılı sonuçlar bildirilmiştir. ${ }^{[24]}$ 


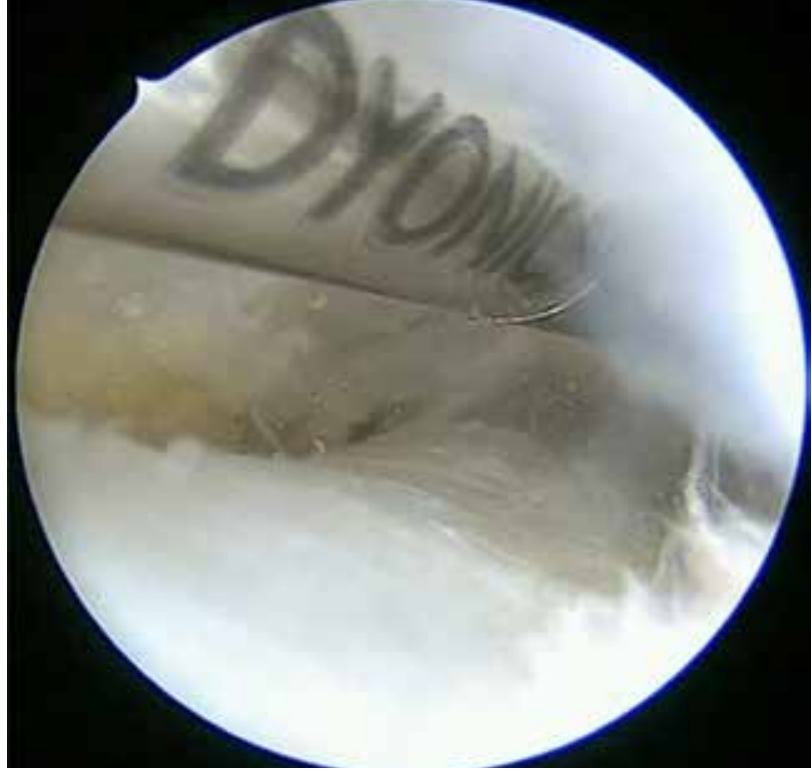

Şekil 3. Portallerin oluşturulmasının ardından shaver cihazının proksimal portalden girişi.

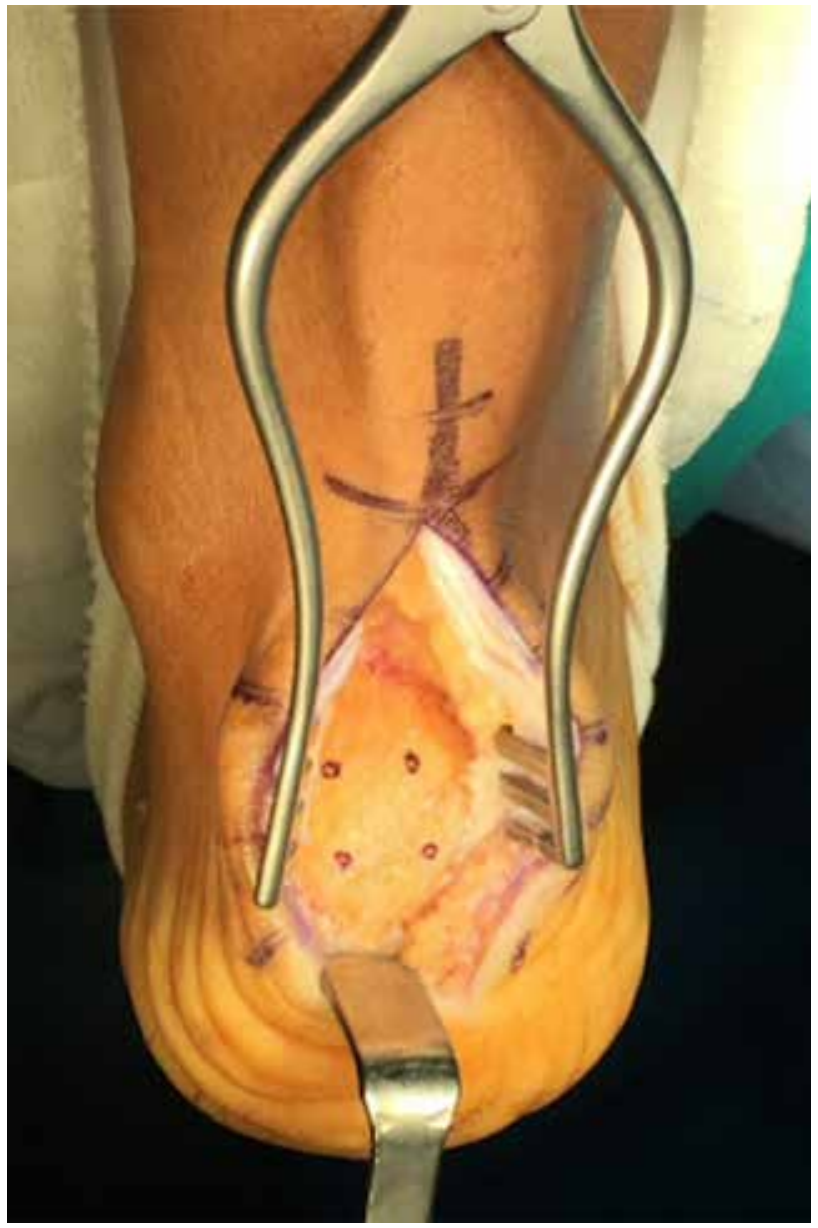

Şekil 5. Posteriordan yapılan orta hat insizyonu ile Aşil tendonunun split olarak açılması ve ankor pozisyonlarının planlanması.

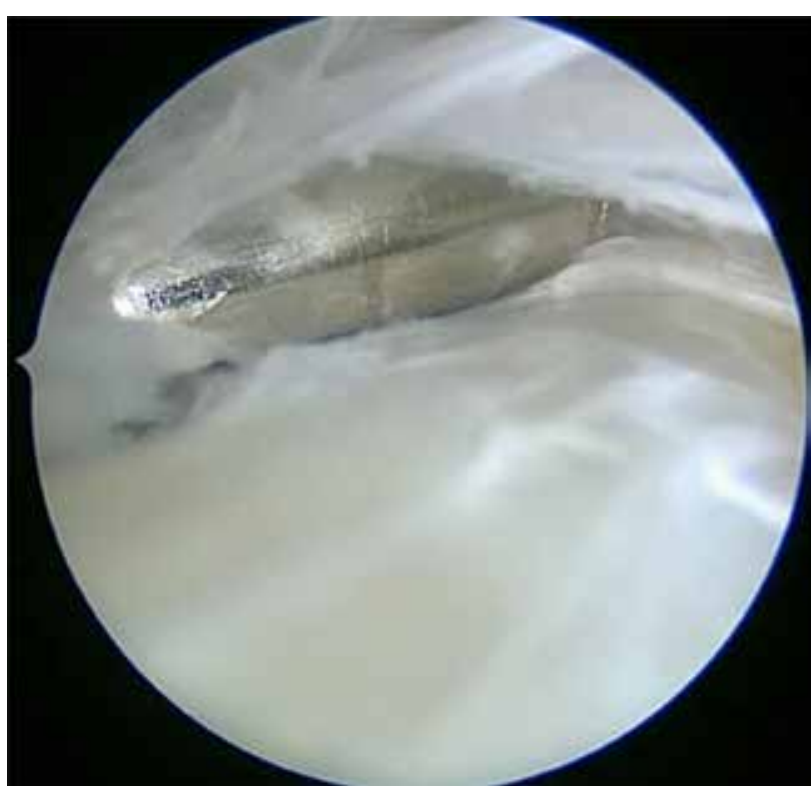

Şekil 4. Shaver ile Aşil tendonu ve paratenon arsındaki aralıktan yapılan tüm yapışıklıkların debride edilmesi.

Tendonu orta hattan ayırdıktan sonra kemik eksizyonu ve debridmanın ardından tendonun yeniden tamiri sırasında farklı yöntemler bildirilmiştir. Tek ankor, çift ankor ve çift sıra tamirler sıkça kullanılan yöntemlerdir. Yapılan çalışmalarda en az iki ankor kullanılarak yapılan tamirlerin fonksiyonel sonuçlarının, tek ankorla yapılanlarla karşılaştırıldığında anlamlı olarak daha iyi olduğu gösterilmiştir. ${ }^{[25]}$ Çift ankor kullanılarak tamir yapılan başka bir çalışmada, bir yıllık takip sonrası 39 hastada mükemmel sonuçlar bildirilmiştir. ${ }^{[26]}$ Bu çalışmada, hastaların bir kısmına FHL transferi de uygulanmış, ancak her iki grubun sonuçları arasında anlamlı bir fark bulunmamıştır.

Tendonu orta hattan ayırarak yapılan ve çift ankor ile tespit sağlanan olgularda yapılan uzun dönemli çaIışmalarda, ortalama 5,7 ay içinde ağrının tamamen geçtiği, dört yıllık takiplerde 22 hastanın 11'inde kalsifikasyonun yeniden gözlendiği, ancak yedi yıllık takiplerde hastaların \%96'sının semptomsuz ve cerrahi tatminin yüksek olduğu bildirilmiştir. ${ }^{[25]}$

Çift sıra ankor kullanılarak yapılan tamirler, daha geniş tendon yapışma yüzeyi ve erken yük verme ve rehabilitasyon sağlanabileceği düşünüldüğünden, artan yaygınlıkla uygulanılmaktadır (Şekil 6). Çift sıra tekniğin, tek sıra ile karşılaştırıldığında, daha yüksek kopma kuvvetine sahip olduğunu gösteren biyomekanik çaIışmalar mevcuttur. ${ }^{[27]}$ Teorik olarak düğüm irritasyonu olmayacağı için, düğümsüz çift sıra ankorların dügümlü olan versiyonlarına göre daha avantajlı olacağı 


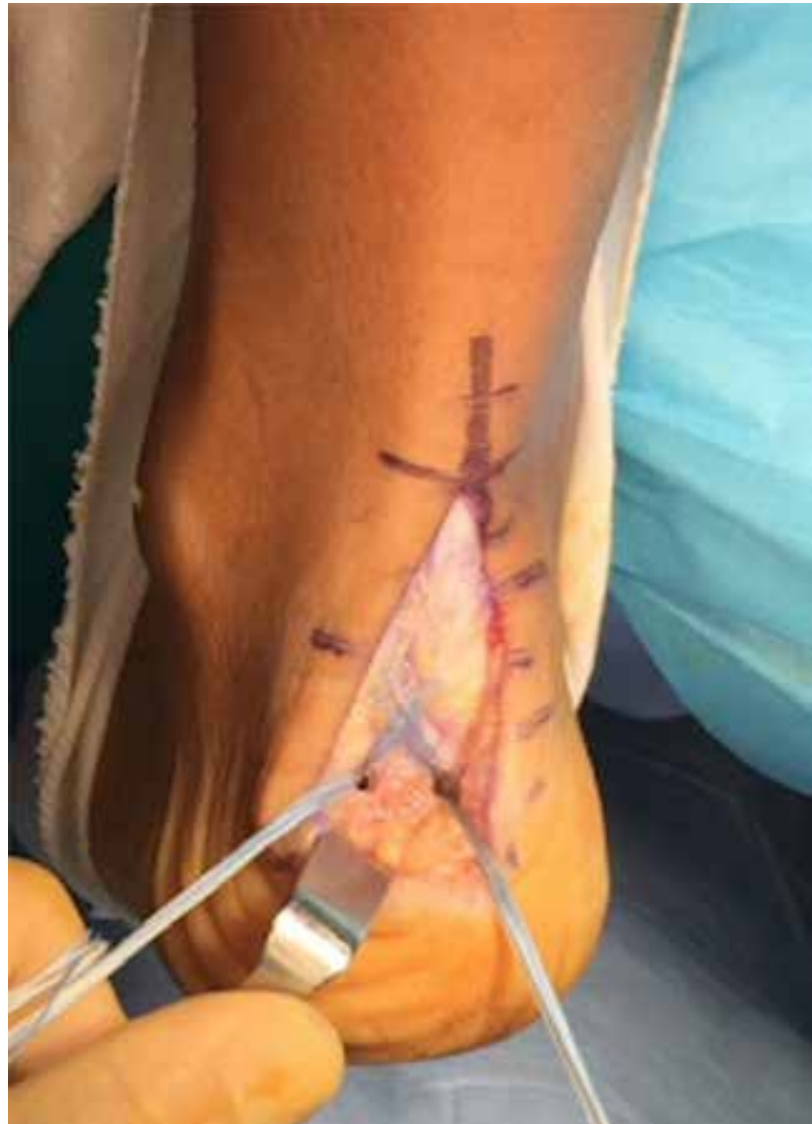

Şekil 6. Çift sıra tamir sonrası Aşil tendonunun görünümü.

düşünülmektedir. Ancak, biyomekanik çalışmalar düğümsüz sistemlerin dügüumlülerden daha düşük kopma kuvveti olduğunu göstermiştir. ${ }^{[28]}$

Yine de, hiçbir tamir tekniğinin normal yürüme sırasında Aşil tendonun pik kopma kuvveti olan 1430 N'a yaklaşamadığı bilinmektedir. Buna rağmen, en yüksek dayanıklılığın $434 \mathrm{~N}$ ile çift sıra tamir tekniğinde olduğu ve daha erken rehabilitasyona izin verdiği akılda tutulmalıdır.

\section{FHL Augmentasyonu}

Aşil tendon debridmanı sonrası yapısal destek sağlanması için, FHL kalkaneal tüberositeye transfer edilebilir. Yapısal desteğin yanı sıra FHL kas gövdesinin yüksek perfüzyon kapasitesi nedeni ile, dejenere Aşil tendonunun perfüzyonunu arttırdığı ve biyolojik iyileşme sürecine de destek olduğu düşünülmektedir. ${ }^{[29-32]}$ Genel olarak kabul edilen, Aşil tendonunun \%50'den daha fazlasının debridmanı gerektiğinde, tendon avulsiyonu riskini ortadan kaldırmak için FHL transferinin planlanmasıdır. ${ }^{[33]}$ Farklı greft yöntemleri olmakla birlikte, genel olarak tek insizyon tekniği ile başarılı sonuçlar bildirilmiştir. ${ }^{[34]}$ Hunt ve ark. tarafından yapılan çalışmada, 50 yaş üzeri 39 hastada FHL transferi sonrası klinik sonuçlarda fark olmadığı gösterilmiş ve bu, transfer gerekliliğinin sorgulanmasına neden olmuştur. ${ }^{[26]}$

\section{SONUÇ}

İnsersiyonel Aşil tendinopatisinin tedavisinde farkIı cerrahi yöntemler tanımlanmıştır. Etkin debridman, semptomların gerilemesinde oldukça önemli olup, neredeyse tendonun tamamının kaldırılmasını gerektirmektedir. En az iki ankor kullanılarak yapılan tamirin optimal sonuçları sağladığı gösterilmekle birlikte, artan yaygınlıkta kullanımı çift sıra tamirin başarısını göstermektedir. FHL transferinin tedaviye eklenmesinin sonuçları olumlu etkilediği ile ilgili çalışmalar yetersizdir. Güncel literatür ışı̆̆ında; etkin debridman, kuvvetli tamir ve erken rehabilitasyon - mobilizasyonla optimal sonuçlara ulaşılabileceği ve spora dönüşün ameliyat sonrası 5.-6. ayda mümkün olabileceği akılda tutulmalıdır.

\section{KAYNAKLAR}

1. Jozsa L, Kannus P. Overuse injuries of tendons. In: Jozsa L, Kannus P, editors. Human Tendons: Anatomy, Physiology and Pathology. Champaign: Human Kinetics; 1997. pp.164-253.

2. Ames PR, Longo UG, Denaro V, Maffulli N. Achilles tendon problems: not just an orthopaedic issue. Disabil Rehabil 2008;30(20-22):1646-50. Crossref

3. Maffulli N, Khan KM, Puddu G. Overuse tendon conditions: time to change a confusing terminology. Arthroscopy 1998;14(8):840-3.

4. van Dijk CN, van Sterkenburg MN, Wiegerinck JI, Karlsson J, Maffulli N. Terminology for Achilles tendon related disorders. Knee Surg Sports Traumatol Arthrosc 2011;19(5):835-41. Crossref

5. Frairia R, Berta L. Biological effects of extracorporeal shock waves on fibroblasts. A review. Muscles Ligaments Tendons J 2011;1(4):138-47.

6. Sayana MK, Maffulli N. Eccentric calf muscle training in nonathletic patients with Achilles tendinopathy. J Sci Med Sport 2007;10(1):52-8. Crossref

7. Kreiner $\mathrm{F}$, Galbo $\mathrm{H}$. Elevated muscle interstitial levels of pain inducing substances in symptomatic muscles in patients with polymyalgia rheumatica. Pain 2011;152(5):1127-32. Crossref

8. Kvist M. Achilles tendon injuries in athletes. Ann Chir Gynaecol 1991;80(2):188-201.

9. Maffulli N. Augmented repair of acute Achilles tendon ruptures using gastrocnemius-soleus fascia. Int Orthop 2005;29(2):134. Crossref

10. Maffulli N, Walley G, Sayana MK, Longo UG, Denaro V. Eccentric calf muscle training in athletic patients with Achilles tendinopathy. Disabil Rehabil 2008;30(20-22):1677-84. Crossref

11. Zwiers R, WiegerinckJI, van Dijk CN. Treatment of midportion Achilles tendinopathy: an evidence-based overview. Knee Surg Sports Traumatol Arthrosc 2016;24(7):2103-11. Crossref 
12. Leppilahti J, Karpakka J, Gorra A, Puranen J, Orava S. Surgical treatment of overuse injuries to the Achilles tendon. Clin J Sport Med 1994;4:100-7.

13. Leach RE, Schepsis AA, Takai $H$. Long-term results of surgical management of Achilles tendinitis in runners. Clin Orthop Relat Res 1992;(282):208-12.

14. Wapner KL, Taras JS, Lin SS, Chao W. Staged reconstruction for chronic rupture of both peroneal tendons using Hunter rod and exor hallucis longus tendon transfer: a longterm follow-up study. Foot Ankle Int 2006;27(8):591-7. Crossref

15. Tallon C, Coleman BD, Khan KM, Maffulli N. Outcome of surgery for chronic Achilles tendinopathy. A critical review. Am J Sports Med 2001;29(3):315-20. Crossref

16. Maffulli N, Binfield PM, Moore D, King JB. Surgical decompression of chronic central core lesions of the Achilles tendon. Am J Sports Med 1999;27(6):747-52. Crossref

17. Maffulli N, Testa V, Capasso G, Bifulco G, Binfield PM. Results of percutaneous longitudinal tenotomy for Achilles tendinopathy in middle- and long-distance runners. Am J Sports Med 1997;25(6):835-40. Crossref

18. Testa V, Capasso G, Benazzo F, Maffulli N. Management of Achilles tendinopathy by ultrasound-guided percutaneous tenotomy. Med Sci Sports Exerc 2002;34(4):573-80.

19. Longo UG, Ramamurthy C, Denaro V, Maffulli N. Minimally invasive stripping for chronic Achilles tendinopathy. Disabil Rehabil 2008;30(20-22):1709-13. Crossref

20. van Sterkenburg $\mathrm{MN}$, van Dijk CN. Mid-portion Achilles tendinopathy: why painful? An evidence-based philosophy. Knee Surg Sports Traumatol Arthrosc 2011;19(8):1367-75. Crossref

21. Paavola $M$, Kannus $P$, Järvinen $T A$, Khan $K$, Jozsa $L$, Järvinen $M$. Achilles tendinopathy. J Bone Joint Surg Am 2002;84-A(11):2062-76.

22. Shakked RJ, Raikin SM. Insertional Tendinopathy of the Achilles Debridement, Primary Repair, and When to Augment. Foot Ankle Clin 2017;22(4):761-80. Crossref

23. Yodlowski ML, Scheller AD Jr, Minos L. Surgical treatment of Achilles tendinitis by decompression of the retrocalcaneal bursa and the superior calcaneal tuberosity. Am J Sports Med 2002;30(3):318-21. Crossref
24. Ettinger S, Razzaq R, Waizy H, Claassen L, Daniilidis K, Stukenborg-Colsman C, Plaass C. Operative Treatment of the Insertional Achilles Tendinopathy Through a Transtendinous Approach. Foot Ankle Int 2016;37(3):288-93. Crossref

25. Nunley JA, Ruskin G, Horst F. Long-term clinical outcomes following the central incision technique for insertional Achilles tendinopathy. Foot Ankle Int 2011;32(9):850-5. Crossref

26. Hunt KJ, Cohen BE, Davis $\mathrm{WH}$, Anderson RB, Jones $\mathrm{CP}$. Surgical Treatment of Insertional Achilles Tendinopathy with or Without Flexor Hallucis Longus Tendon Transfer: A Prospective, Randomized Study. Foot Ankle Int 2015;36(9):998-1005. Crossref

27. Beitzel K, Mazzocca AD, Obopilwe E, Boyle JW, McWilliam J, Rincon L, Dhar Y, Arciero RA, Amendola A. Biomechanical properties of double- and single-row suture anchor repair for surgical treatment of insertional Achilles tendinopathy. Am J Sports Med 2013;41(7):1642-8. Crossref

28. Cox JT, Shorten PL, Gould GC, Markert RJ, Barnett MD Jr, Laughlin RT. Knotted versus knotless suture bridge repair of the achilles tendon insertion: a biomechanical study. Am J Sports Med 2014;42(11):2727-33. Crossref

29 Wapner KL, Pavlock GS, Hecht PJ, Naselli F, Walther R. Repair of chronic Achilles tendon rupture with flexor hallucis longus tendon transfer. Foot Ankle 1993;14(8):443-9.

30. Hahn F, Meyer P, Maiwald C, Zanetti M, Vienne P. Treatment of chronic Achilles tendinopathy and ruptures with flexor hallucis tendon transfer: clinical outcome and MRI findings. Foot Ankle Int 2008;29(8):794-802. Crossref

31. Martin RL, Manning CM, Carcia CR, Conti SF. An outcome study of chronic Achilles tendinosis after excision of the Achilles tendon and flexor hallucis longus tendon transfer. Foot Ankle Int 2005;26(9):691-7. Crossref

32. Wilcox DK, Bohay DR, Anderson JG. Treatment of chronic achilles tendon disorders with flexor hallucis longus tendon transfer/augmentation. Foot Ankle Int 2000;21(12):1004-10.

33. Kolodziej P, Glisson RR, Nunley JA. Risk of avulsion of the Achilles tendon after partial excision for treatment of insertional tendonitis and Haglund's deformity: a biomechanical study. Foot Ankle Int 1999;20(7):433-7. Crossref

34. Den Hartog BD. Flexor hallucis longus transfer for chronic Achilles tendonosis. Foot Ankle Int 2003;24(3):233-7. Crossref 